\title{
What do GPs actually know about their patients as persons?
}

\author{
Bente Prytz Mjølstad MD ${ }^{\mathrm{a}}$, Anna Luise Kirkengen MD DrMed ${ }^{\mathrm{b}}$, Linn Getz MD PhD ${ }^{\mathrm{c}}$ and Irene \\ Hetlevik MD DrMed ${ }^{d}$
}

a PhD Student, General Practice Research Unit, Department of Public Health and General Practice, Norwegian University of Science and Technology (NTNU), Trondheim, Norway

b Professor, General Practice Research Unit, Department of Public Health and General Practice, Norwegian University of Science and Technology (NTNU) Trondheim; Institute of Community Medicine University of Troms $\varnothing$ Senior Researcher, Centre for Health Promotion, University Hospital Akershus, Norway

c Professor, General Practice Research Unit, Department of Public Health and General Practice, Norwegian University of Science and Technology (NTNU), Trondheim, Norway \& Staff Physician, Landspitali University Hospital of Iceland, Iceland d Professor and Leader, General Practice Research Unit, Department of Public Health and General Practice, Norwegian University of Science and Technology (NTNU), Trondheim, Norway

\begin{abstract}
Background and Aims: Life experience and existential circumstances have an impact on health. Within medicine, however, the significance to patient care of person-related, biographical knowledge receives only rudimentary emphasis and its substantial theoretical underpinnings are inadequately understood and infrequently applied. This study explores the types and extent of some Norwegian general practitioners' (GPs') person-related knowledge, exemplified by patients on the GPs respective lists who are currently in a state of frail health.

Methods: Nine GPs were interviewed regarding one of their patients who had recently been admitted to the rehabilitation unit of a nursing home. Subsequent interviews with the individual patients served both to validate the GPs' information and as a starting point for further inquiry into patient life stories. Interview transcripts were analyzed within a phenomenological-hermeneutical framework.

Results: Most GPs were able adequately to characterize the personality of their patients and had acquired substantial knowledge about their occupation and closest family relationships. The GPs tended to have less knowledge regarding patients' interests, hobbies, social network and their relationships to their parents and siblings. They had the least knowledge about patients' childhood, upbringing and social background. Some GPs reacted with surprise or embarrassment when becoming aware of potentially significant "knowledge holes” regarding patients whom they had known for years.

Conclusions and implications: We document limitations to healthcare professionals' eliciting of knowledge about their patients as persons. A long-term doctor-patient relationship seems to enable GPs to identify and articulate their patients' personal characteristics. It does not ensure that the GPs will accumulate knowledge regarding those biographical facts or experiences that, particularly during transitions to other caretakers, might prove most salient to their patients' health and treatment. We believe the findings to have relevance both for clinical practice and medical education, but further research and reflection is needed before formal changes in current practice are to be recommended.
\end{abstract}

\section{Keywords}

Comparison of interviews, GP-patient relationship, information transfer among caretakers, patients as persons, patient transfer, person-centered medicine, primary care, qualitative research

\section{Correspondence address}

Dr. Bente Prytz Mjølstad, General Practice Research Unit, Department of Public Health and General Practice, Norwegian University of Science and Technology, PO Box 8905, 7491 Trondheim, Norway. E-mail: bente.mjolstad@ntnu.no

Accepted for publication: 4 October 2012

\section{Introduction}

A growing and increasingly detailed and comprehensive body of scientific evidence documents that lifetime experiences and existential circumstances have a significant impact on human health and disease development [1-8]. Currently, however, there exists within the field of medicine only a rudimentary tradition for gathering, transferring and emphasizing such person- related, biographical knowledge, even in the first line of medical care which is served by general practitioners (GPs). The theoretical understanding of the significance of such knowledge has not yet been thoroughly explored [914].

We have recently documented that experienced Norwegian GPs claim to accumulate substantial knowledge over time about their patients as persons. Though they consider such knowledge to be medically 
relevant, they often find it difficult to formulate and record, both for the immediate patient record and for potential transfer to other actors and institutions in the healthcare system [15].

A concrete situation in which the transfer of such patient-related knowledge lacks a formal channel for emphasis, despite its potential relevance, is when an elderly and/or otherwise frail individual is being transferred temporarily to a nursing home for rehabilitation. In Norway, as in many Western societies, the increasing number of aging and elderly frail people poses a major challenge to the public health system. Even though today's elderly are in better health and function at a higher level than those of previous generations, the cognitive and functional impairment and multiple chronic diseases [16] which often accompany old age are likely to result in an increasing proportion of the population ultimately requiring extended primary healthcare services. According to national surveys, most Norwegians prefer to live at home rather than in a nursing home for as long as possible [17]. By prioritizing home-based, primary care, the government seeks to reduce or postpone individuals' need for long-term facilities. Most elderly people living at home function well and can take care of themselves, often with the support of family members and/or municipal home-visit services. Yet, an acute disease or sudden change in life circumstances may critically impair functioning such that short-term rehabilitation and/or a temporary stay at a caretaking nursing home [18,19] become necessary. Most likely, an increasing proportion of the elderly will periodically find themselves "in transit" between their home and an institution. An efficient exchange of relevant knowledge about the patient between the patient's local healthcare provider and the temporary caretaking institution is a prerequisite if rehabilitation during these transitions is to be successful. All citizens in Norway are assigned a GP; this family doctor could be expected to play a central role in the exchange of such information.

Frequently, GPs serve as consulting physicians in nursing homes and, consequently, often participate both in the rehabilitation of disabled and/or chronically ill people of different ages and in the end-of-life care of frail, elderly people [20]. A nursing home doctor (GP or geriatrician), however, particularly one working in more densely populated urban settings, rarely has previous knowledge about patients admitted for rehabilitation.

Medically relevant knowledge, according to the traditional view informing the biomedical basis of contemporary Western healthcare systems, utilizes observable and measurable variables. These facilitate the objectification of bodily functions and symptoms based on the current, established classification systems for diagnosing somatic and mental diseases. Within this natural science framework, human subjectivity, the patient's world of personal experiences, values and relationships, is rarely assessed or treated as relevant [21].

The comprehensive body of knowledge linking the subjective phenomena of personal experience to human health and disease draws upon a variety of scientific disciplines, including, among others: stress research, psychoneuroimmunology, genomics and telomere research. The emerging evidence affirms the impact of someone's biographical experience - her/his interpersonal relationships and human life-world - on that person's body, both its physiology and its functioning. This attests to the fact that mind informs matter. Or, put more concisely: the evidence shows that mind matters [6-8].

In other words, knowledge about "the biological body" in a purely physical and biomolecular sense, might not suffice to capture the essence of a person/patient's functional breakdown or to permit an appropriate characterization of her/his actual needs. To accomplish those goals, knowledge about "the lived body" (the person's embodied life) needs also to be attributed relevance.

\section{Motivation for this Project}

For several years, the first author of this paper alternated between working as a GP, providing primary care to the patients assigned to her practice list and serving as a consulting physician in a nursing home. From these 2 perspectives she was able to observe that information about the personal lives of patients admitted to institutional care seemed to be "lost in transition." Typically, the GPs' referrals included biomedical knowledge about the patient (a medical history and status, list of medications, etc.) but only rarely biographical knowledge about the person beyond strictly demographical data such as gender, civil and occupational status (e.g., life history, salient events, significant relationships, etc.). In her role as GP, the first author experienced repeatedly how central relevant biographical knowledge could be to understanding the circumstances surrounding a sudden deterioration of health. This observation is supported by the writings of the late Barbara Starfield, an authoritative, international primary healthcare researcher [22].

The overall aim of the larger project to which the present study belongs is to explore the medical relevance of person-related knowledge. The project consists of 3 consecutive phases. In the initial, exploratory phase, 2 groups of GPs were invited to reflect upon and discuss the potential significance of having knowledge about their assigned patients as persons. The participating GPs in that study were confident that they possessed medically relevant knowledge about their patients' life-world, for example, in the case of admission for rehabilitation [15]. In this second part of the project, as outlined in this paper, we explore the knowledge the GPs actually have about their patients as persons by comparing the information the GPs share to the narratives offered by the patients themselves. In a third paper, in preparation, we will compare GPs' proposed aims for their patients' institutional stay (as communicated to the researchers during telephone interviews) with the actual treatment plan that the staff of the rehabilitation unit eventually developed. 


\section{Theoretical Framework}

A combination of phenomenological and hermeneutical principles (interpretations) [23-25] provides a research framework well suited to exploring and reflecting upon human experience within medicine and medical practice, investigating what GPs know about their patients as persons and comparing that to the patients' own account. The methodological perspective of phenomenology facilitates entering into the interviewee's world of subjective and personal experiences without disturbing the context in which these manifest. Since an investigation of human experience as communicated through first-person accounts involves an exploration of value systems and of symbols as they are conceptualized and expressed in language, both spoken and written, the researcher is well served by being conversant with hermeneutics.

For our conceptual differentiation of a "patient" from a "person," we have relied upon Eric Cassell's definition, distinguishing a philosophically-based state of personhood from the social role of patient, one which is imposed by disease and defined by pathology-oriented biomedicine [26]. According to Cassell, a person is "an embodied, purposeful, thinking, feeling, emotional, reflective, relational, human individual always in action, responsive to meaning and whose life in all spheres points both outward and inward. Virtually all of a person's actions volitional, habitual, instinctual or automatic - are based on meanings" [27]. Since meaning and personhood are mutually constituted, statements about persons are statements about values and social phenomena.

\section{Method}

The present study was conducted at the rehabilitation unit of an urban nursing home in central Norway. The recruited patients had been admitted for a short-term stay (2-3 weeks) due to some impairment to their ability to function in their home setting. Potential participants, deemed competent to grant informed consent, were identified by the unit staff, told about the existence of the study and, finally, asked to sign written consent forms. Only then did the first author contact those patients' regular GPs to request their own agreement to participate in the study.

Once both the patients and GPs formal consent had been obtained, the first author scheduled a 10-15 minutes' telephone interview with the GP, focused on the topic: "What can you tell me about patient NN as a person that might have relevance for this stay?” The GP interview was structured (see interview guide, Figure 1), audiotaped and transcribed, verbatim, by the first author. A face-to-face interview was conducted with the patient shortly after the GP interview, lasting typically for one hour. Each patient interview began with the first author presenting a condensed version of the information that their GP had shared with the researcher and granted explicit permission to share with the patient. The patient was encouraged to correct, deepen or supplement this information immediately. Field notes commenting on interview settings and interviewees' nonverbal and/or paraverbal responses (voice tone, pitch and pacing) completed the data sets for each of the study's patient/GP participant pairs.

The Regional Committee for Medical Research Ethics for Central Norway approved the overall project, including the present study. All participating patients and GPs received written information and supplied, as required, their signed, informed consent prior to being included.

\section{Figure 1 The topics of the interview guide. The} order of the topics varied among the interviews

\author{
What can you tell me about this patient as a person - \\ with relevance for this stay? \\ - $\quad$ Personality \\ - Relationship to immediate family (spouse, children, \\ partner) \\ - Occupation - working life \\ - Life events (significant/ important for health/ illness) \\ - Interests - Hobbies (leisure activities) \\ - Social network - friends, acquaintances \\ - $\quad$ Relationship to parents and siblings \\ - $\quad$ Social background - childhood, upbringing (origin)
}

\section{Participants}

Patients invited to participate in the study were living at home, were expected to return to their homes after rehabilitation, whose relationship to their current GP had been ongoing for more than 2 years and who were competent to provide informed consent. Eligible patients were added consecutively. Professional information about the GPs (age, number of assigned patients, number of doctors sharing their offices) (Table 1) was compiled from official registers.

\section{Analysis}

In a previous study [15] we focused on what, in general, it is like to be a GP who knows her/his patients' biography and especially when cooperating with other parts of the healthcare system. In the present study, we investigate more concretely what person-related knowledge GPs actually tend to have. We found it relevant to exemplify this by focusing on patients on the GPs' lists who were currently in a vulnerable state of health, documented by the fact that they had been admitted for rehabilitation. Our analytic approach is inspired by Kvales' tri-level phenomenological-hermeneutical analysis. The findings in this paper involve primarily his second and third analytical level. Level 2 involves interpretations based on general understanding and common sense; this is double-layered, being both subjectively and objectively focused. 
Table 1 Characteristics of the participants

\begin{tabular}{|c|c|c|c|c|c|c|c|c|c|}
\hline \multirow{2}{*}{ Participants } & \multicolumn{4}{|c|}{ Patients } & \multirow{2}{*}{$\begin{array}{c}\text { D/P } \\
\text { relationship } \\
\text { (years) }\end{array}$} & \multicolumn{4}{|c|}{ Doctors } \\
\hline & Gender & $\begin{array}{c}\text { Age } \\
\text { (years) }\end{array}$ & $\begin{array}{c}\text { Civil } \\
\text { status }\end{array}$ & $\begin{array}{c}\text { Disease, } \\
\text { conditions }\end{array}$ & & Gender & $\begin{array}{c}\text { Age } \\
\text { (years) }\end{array}$ & $\begin{array}{c}\text { Listed } \\
\text { patients }\end{array}$ & $\begin{array}{l}\text { Doctors at } \\
\text { the office }\end{array}$ \\
\hline A & $\mathrm{M}$ & 83 & Married & $\begin{array}{c}\text { Parkinsons } \\
\text { disease }\end{array}$ & 25 & $\mathrm{M}$ & 58 & 1850 & 3 \\
\hline B & $\mathrm{M}$ & 44 & Married & CFS & 23 & $\mathrm{M}$ & 61 & 1100 & 5 \\
\hline C & $\mathrm{M}$ & 58 & $\begin{array}{c}\text { Single } \\
\text { Divorced }\end{array}$ & MS & 13 & $\mathrm{M}$ & 51 & 1550 & 4 \\
\hline D & $M$ & 58 & Married & Stroke & 10 & $\mathrm{M}$ & 53 & 1300 & 7 \\
\hline E & $F$ & 46 & $\begin{array}{c}\text { Single } \\
\text { Divorced }\end{array}$ & $\begin{array}{c}\text { Sequels; brain } \\
\text { abscess }\end{array}$ & 18 & $F$ & 53 & 1300 & 4 \\
\hline $\mathbf{F}$ & M & 84 & Married & Hip fracture & 24 & $\mathrm{M}$ & 57 & 1400 & 5 \\
\hline G & $\mathrm{M}$ & 57 & Single & $\begin{array}{l}\text { Chronic pain, } \\
\text { abuse }\end{array}$ & 10 & $\mathrm{~F}$ & 49 & 1500 & 5 \\
\hline H & $\mathrm{F}$ & 52 & Married & MS & 11 & $M$ & 42 & 1850 & 4 \\
\hline I & $F$ & 94 & Widow & $\begin{array}{c}\text { Glaucoma, } \\
\text { advanced age }\end{array}$ & 3 & $\mathrm{~F}$ & 34 & 1650 & 5 \\
\hline
\end{tabular}

$\mathrm{CFS}=$ chronic fatigue syndrome; $\mathrm{MS}=$ multiple sclerosis; $\mathrm{D} / \mathrm{P}$ relationship = duration of doctor/patient relationship ; $\mathrm{M}=$ male, $\mathrm{F}=$ female

Level 3 aims at understanding these findings through the application of existing theories [23]. Our analysis' point of departure was a comparison of GPs' statements regarding their patients as persons (Figure 1) to those made by the patients themselves, in order to assess the GPs' familiarity with various aspects of each patient's life. The integration of the findings into theoretical frameworks (level 3) is presented in the discussion below.

\section{Results}

\section{Characteristics of study participants}

From February 2010, through April 2011, 25 eligible patients were admitted to the rehabilitation unit directly from their homes (not from other institutions or hospitals). Sixteen of these patients were excluded from this study due to: administrative lapses (6), incapacity to consent (4), a preference for not participating (3 patients and $3 \mathrm{GPs}$ ). The remaining 9 patients and their respective GPs were enrolled, consecutively, in the study.

Selected characteristics of participating patients and GPs are presented in Table 1. The mean patient age was 64 years (44-94 years) and that of GPs was 51 years (34-61 years). The mean duration of the doctor-patient relationships was 15 years (3-25 years). All doctors were experienced GPs working full time at healthcare centers with at least 2 colleagues. Only 2 of the admitted patients shared the same primary diagnosis (multiple sclerosis).

\section{Comparisons of statements}

The following is an annotated presentation of our comparison (second analytical level) of the GPs' statements regarding various aspects of their patients as persons, with the patients' corroborations.

\section{The GPs' statements concerning their patients as persons}

\section{Aspects of their patients' lives about which the GPs have comprehensive knowledge}

Nearly all GPs described the personal traits of patients in a way that was later validated by the patients themselves. Most GPs were also quite familiar with each patient's immediate relationships and occupational life (Figure 2).

\section{Personal characteristics of their patients}

In the following excerpt from a dialogue between the interviewer (I) and patient A (PA), the interviewer recounts GP statements concerning some of the patient's characteristics, which are corroborated by PA:

I: I asked your GP how he would characterize you as a person. He responded in a nice way, stating that: "PA he's very steady and firm. A steadfast man.”

PA: Yes. [smiles]

I [continues to quote]: "I think he must have been a fantastically good Captain - very conscientious, steady 
and firm.” He also stated that he believes you're "not someone who enjoys talking about things - but rather prefers to keep things to himself.”

PA: Yes, that's right!

I: And: "He’s someone to be trusted..."

PA: Yes.

I: Can you recognize yourself in this description?

PA: Yes, I can! [sounding a bit astonished]

\section{Relationships with immediate family (spouse, children, partner)}

Although patient E's closest family relationships are quite complex, when asked about this topic the GP easily provides extensive, detailed yet concisely expressed information:

\begin{abstract}
"She lives alone in her own apartment, has 4 children with her ex-husband and one child with her latest expartner, but she's not capable of caring for these children on a daily basis. The children from her first marriage are old enough to visit her on their own - but she has limited contact with them. Or, more precisely, she doesn't have custody of her youngest child, who was born in April, 2007. The 4 older children live with their father - her ex-husband. That is, the oldest son lives on his own. So there are 3 children living with the ex-husband - and the youngest son lives with his father."
\end{abstract}

In an excerpt from the dialogue between the interviewer (I) and patient E (PE), the patient corroborates this information as follows:

I: So you live alone - and your GP told me that you are the mother of 5 children?

PE: Yes, I am!

I: And that 4 of these children live with your exhusband?

PE: Yes - and he’s Norwegian.

I: ... and that you also have one child with another man?

PE: Yes - and he’s Finnish!

I: And the youngest child is a 3-year old boy?

PE: 3 1/2- years old. His name is "Tom.”

I: But your GP also told me that, after falling ill, you've experienced difficulties taking care of the children on your own?

PE: Yes. But they visit me frequently; they're between 3 and 20 years old.

\section{Occupational life}

General practitioner C's information concerning patient C's occupation includes a description of the patient as a person and how the disease has affected him:

"Before he fell ill, he was a likeable person with a lot of empathy and compassion and plenty of resources. He had lots of interests and hobbies; he used to be a longdistance runner and trained to run marathons, but motorcycles were his main hobby. I got the impression that he had a lot of friends and a passion for soccer both English and Norwegian soccer teams. He used to work as a therapist at a rehabilitation center and took care of people who abused drugs and alcohol. He very much enjoyed his work and his colleagues supported him a lot when he got ill. They put him to work for a while - even working nightshifts though without salary - so they wouldn't lose contact. For some time, they also had him making contact with clients by phone. Gradually he became incapable of working, went on sick leave and finally on a disability pension. He hasn't been able to perform any work for the last 3 years.”

In the following interview, patient $\mathrm{C}$ both corroborates and corrects this information:

I: GP C mentioned your occupational life; as far as he could remember - and before you got sick - you used to work at $\mathrm{X}$ rehabilitation center?

PC: No - it was X treatment center

I: Treatment center? Yes, that’s something different!

PC: Yes - it’s active treatment for substance abusers.

I: Yes. He told me that you used to work there as, "a therapist who took care of people with drug and alcohol abuse."

PC: Yeah - that's a way to put it.

I: And he told me that you enjoyed your work?

PC: Hmm - yes - I had a great time working there! I had a lot of good friends there as well.

I: And GP C had noticed that your colleagues at work supported you a lot after you became ill?

PC: Yes - that's right! [Memories apparently come back; his face brightens up]

\section{Aspects of their patients' lives about which the GPs have limited knowledge}

Significant holes in the GPs knowledge regarding earlier major events in their patients' biographies were revealed in several of the paired interviews. Our use of the term "significant" here refers to the fact that the experiences and events in questions have documented medical relevance to health. In addition the GPs tended to have little knowledge regarding the patients' interests, hobbies and social network or of their patients' relationships to their parents 
or siblings. The GPs had least information regarding the patients' childhood, upbringing and social background (Figure 2).

\section{Major life events with probable relevance to health}

The GPs were asked to relate important events in their patients' lives with probable medical relevance, defined as: major changes or disruptions that could evoke distress (such as divorce or a relationship break-up), serious accidents or the death of a close relative. Most GPs had some knowledge of potentially distressing life events, although they were not necessarily cognizant of the events' inherent relevance to their patient's health. This was the case for GP D who suddenly became aware of a note in patient D's medical record about the long-ago death of a child but was unable to provide any details about this loss. In the successive interview, patient $\mathrm{D}$ spoke with the researcher about the death of this son even though this still evoked strong emotions. Without hesitation, he also brought up a related and important, but apparently taboo topic:

I: GP D found some information in your records concerning the death of a child. He believed that you had lost a child - but he didn't know how - and believed that this had happened before he became your doctor.

PD: Yes, that happened before. This was something I couldn't talk about at home. The relationship between me and my wife wasn't strong enough for that, because the child was the result of infidelity. The boy died in an accident when he was 5 . The boy's mother and her family refused to notify me of his death. I had to go to the police to have it verified. They obviously didn't want me come to his funeral... [his voice cracks]

\section{Interests and current social network}

Most GPs had little or no information about their patients' interests, hobbies, friends and acquaintances; some GPs who seemed uncertain about a patient's social life went on to speculate as to what activities, such as watching TV, that the patient might find interesting. When asked by the interviewer, however, most patients, such as patient $\mathrm{D}$, willingly revealed detailed and comprehensive information concerning their interests and social life:

I: I asked GP D if he knew about any of your interests or hobbies, and he said he didn't have much knowledge about this topic. He believed you probably enjoyed watching TV and listening to the radio, but didn't know if you enjoyed reading.

PD: Well, reading is okay, but when you talk about TV and especially sports channels - I can watch sports for days and nights on end. I'm interested in all kind of sports - as long as it isn't ice hockey or horse show jumping - but especially biathlon. You know, I've been watching a lot more TV since I got sick, sitting in my wheelchair - because there are a lot of things I'm not able to do anymore. I used to enjoy life outdoors and when I was younger, I was into sports.

\section{Relationship to parents and siblings}

In contrast to knowledge regarding their patients' children, spouses or partners, most GPs had only limited information about patients' relationship to their parents and siblings. For example, when the interviewer communicated to patient B the information GP B had reported, he both confirmed it and expanded on it:

I: I asked GP B about your family when you were growing up. He couldn't recall precisely - but he seems to remember that you had an alcoholic father and that your parents got a divorce. When I asked if you had any brothers or sisters, he couldn't remember.

PB: I have a sister - but we don't have much contact. I was 2 years old when she was born and my father moved out at the same time. I lived with my mother my whole childhood. She remarried and my stepfather was the executive director of a large company in X city, so we moved there. They got divorced when I was 12 and we had to move back again. From that moment on, I had to be the man of the house. During my whole childhood and my teens, my father was there only now and then. When he started drinking - later, after I'd grown up - I had to be the one to straighten things out. I almost had to act as if I was his father.

\section{Childhood, upbringing and social background}

Most of the GPs had limited knowledge, if any, regarding the patients' childhood, upbringing, and social background. The patients all had the physical/mental capacity to discuss such topics and were all, to some extent, also willing to do so with the researcher. Some provided detailed information despite being cognitively affected by their disease, as in the case of patient $\mathrm{H}$ suffering from severe multiple sclerosis:

"I grew up on a farm, living with my parents. I had one older sister and one younger sister and we all had a good relationship, but none of us wanted to take over the farm. My mother lived on that farm until this last year, but then she moved closer to the center of town. She's 84 years old but vigorous! My father died 30 years ago of a stroke. At that time, health personnel didn't emphasize the possibilities for rehabilitation after a stroke - as compared to today's practice. But for him it probably was for the best that they let him die because it was so serious."

The fact that the GPs lacked knowledge about their patients' childhoods did not necessarily mean that there was "nothing of medical relevance there to be known." For example, patient A's childhood history might conceivably have had an impact on his health:

"I was an illegitimate child and my mother died when I was 12 years old. I was adopted by another family and I got 2 foster-sisters. One of them was mentally disabled. My foster parents were nice to me but, of course, they 
Figure 2 Summarizes the GPs' degree of familiarity with their patients as persons as outlined in this study

\begin{tabular}{|l|c|c|c|c|c|c|c|c|c|}
\hline & \multicolumn{7}{|c|}{ The nine patients A-I } \\
\hline GPs' knowledge about: & A & B & C & D & E & F & G & H & I \\
\hline Personality & + & + & + & + & + & + & + & + & $+/-$ \\
\hline Family relations - close & + & + & + & + & + & $+/-$ & $+/-$ & + & - \\
\hline Occupation - working life & + & + & $+/-$ & + & + & + & - & + & - \\
\hline Major life events & + & $+/-$ & + & $+/-$ & + & $+/-$ & $+/-$ & - & - \\
\hline Interests - hobbies & - & $+/-$ & + & - & - & $+/-$ & $+/-$ & - & - \\
\hline Social network - friends & - & + & + & - & - & - & $+/-$ & - & - \\
\hline Relatives - parents, siblings & - & $+/-$ & $+/-$ & - & $+/-$ & - & $+/-$ & - & - \\
\hline Background - childhood & $+/-$ & $+/-$ & $+/-$ & - & - & $?$ & - & - & - \\
\hline
\end{tabular}

could never replace my biological parents. I didn’t have any contact with my biological father during my adolescence, but I did some research after I'd grown up and actually managed to find him.”

Based on the topics addressed in the interview, Figure 2 visualizes the GPs' differing degrees of familiarity with various aspects of their patients as persons. Each patient is designated with a letter from A to I. The overall duration of the doctor-patient relationships (in years) is shown in the bottom horizontal row.

Color code: Dark Grey [+]: the GP reports comprehensive knowledge about the topic; Light Grey [+/-]: the GP has limited/scarce knowledge; White/blank [-]: the GP has no knowledge about the topic. [?] The researcher failed to ask the GP about this specific topic.

Concerning the topic major life events: A "major life event" was defined as a considerable change in the life of the patient or her/his circumstances - for example, a divorce or broken relationship, serious accidents, death of a close relative - that had the potential to evoke stress. Very "usual" life events such as the death of aged relatives (not expected to provoke considerable stress) were not included. Only GPs who reported one or several major life events, which she/he deemed medically relevant, were classified as "dark grey" (comprehensive knowledge). GPs who knew about a major life event but not whether it was medically relevant, were classified as light grey (limited knowledge).

\section{GPs responses to discovering their "knowledge holes"}

During the telephone interviews, the GPs evinced a variety of reactions when becoming aware how little knowledge they had regarding certain aspects of their patients' lives. Their voices and/or the words they chose expressed emotions ranging from embarrassment - sometimes even shame - to surprise, as exemplified by the following exchange:

GP A sounded surprised when realizing that, despite having been patient A's GP for more than 25 years, he could only surmise what the man's interests might be. He had little information to recount. He presumed, based on the patient's having been a sea captain, that the man had been interested in maritime topics. The patient interview, on the other hand, revealed that patient $\mathrm{A}$ was, in fact, interested in hunting and in raising dogs. He had spent most of his spare time the past several years at his cabin, hunting and fishing.

The doctor-patient relationship between GP D and patient D had been ongoing for 10 years. GP D seemed to be aware that his knowledge about patient $\mathrm{D}$ as a person was somewhat shallow and, during the interview, seemed to feel the need to justify and excuse his lack of knowledge. GP D explained that, even after the patient had a major stroke, few consultations had taken place: 
"Over the years I've known him, there have only been a few occasions when we actually met. Most of the time, he only needed my help to adjust his medications, apply for rehabilitation, renew prescriptions and so on. He hasn't often consulted me at my office and I've only made a few home visits. We've managed to solve problems in alternative ways. His wife has been his spokesperson and the one providing information and exchanging messages, communicating with the personnel at the health center - or with me, if necessary”

The doctor-patient relationship of the shortest duration, only 3 years, was between patient I and her GP. The telephone interview with GP I lasted only 4 minutes because her knowledge regarding the patient was so limited. After repeatedly replying, "I don't know,” GP I, obviously embarrassed, burst out:

\section{"You could have picked somebody else - one of the patients I know better!"}

GP G seemed almost shameful when she was asked about patient G's occupational history and discovered that she knew nothing about it:

"I should, of course, have recorded something about this. I know that patient $G$ always has been fond of writing and I wonder if he was once a writer. It's terrible to admit, but I actually don’t know!”

Some of the GPs gave the impression that, in those cases where they had neither recorded nor could recall anything extraordinary, they had assumed everything was "normal." When uncertain about a given topic, some expressed the assumption that there had probably been nothing of interest to be known about that area:

Though GP F had known patient F for 24 years, he had no knowledge to recount when asked about the patient's "friends and relatives." He said that he had had the impression that everything was "normal" and that the patient had an "ordinary" social network and was not, at any rate, "an odd character."

\section{Disc ussion}

The first author's professional experience, accumulated while alternating between the roles of GP and consultant, inspired this inquiry. She became aware of what might be called "the presence of a medically relevant absence," that is, the person-related information that, despite the health institution's implicit mandate to care for the whole person, is not emphasized when vulnerable patients are moved from their home to a rehabilitation unit at a nursing home. Analysis of the project material revealed what we have come to see as 4 interwoven patterns.

The first pattern concerns those categories of conditions or details of a patient's biography and lifeworld that the 9 interviewed doctors were actually familiar with. There emerged, despite the variety of patient ages and cause(s) for admission, a fairly homogeneous overall pattern of familiarity, as we label it. We attribute this trend towards homogeneity to physicians' common professional socialization, reflecting both what types of information they are trained to inquire about, attend to and record for medical purposes within a doctor-patient-relationship, as well as what they learn to treat as being of minor or negligible relevance. The rules governing which topics are deemed relevant and appropriate in the context of a clinical encounter have been extensively delineated and discussed by a large number of scholars, among whom we choose to cite Stephen Toulmin [28] and Elliot G. Mishler [29].

The second analytical pattern concerns the undercommunicated or missing topics within the GPs' knowledge of their patients, those which are routinely omitted in conversations between doctors and patients and therefore remain unrecorded. These are primarily issues which are traditionally defined as "private," "intimate" or "sensitive" and thus considered either inappropriate to broach and/or irrelevant to the medical problem at hand. This pattern of omission reflects the fact that doctors are dually socialized: they are both medically trained professionals and socio-culturally shaped fellow human beings. These 2 value systems manifest in doctors' encounters with patients as behavioral habits, as has been addressed by scholars within the fields of ethics, philosophy and the social sciences [30,31]. Interestingly, a growing body of consistent evidence indicates that much of what continues to be defined as both "private" and "intimate" and therefore "untouchable" in routine clinical practice does indeed hold medical relevance and ought, therefore, to be discussed [6-8]. We recognize, however, that neither such evidence nor professional ways to interpret and implement it has as yet been integrated into mainstream medical practice.

Furthermore, this identified "pattern of omission" reflects not only a 2-layered socialization of the doctors but also of their patients. Patients have in common a socially and culturally informed awareness of what is appropriate to share with a GP - "to 'burden’ a GP with,” so to speak unless explicitly encouraged to do so. The way contemporary patients in Western societies have been taught to regard the human body in physical and biomolecular terms might well be considered the layman's version of the formal, biomedical education and training doctors receive. Having this view reduces the likelihood that patients would feel free to address the impact that painful life experiences might have had on their subsequent mental and physical ailments, even if, deep down, they may sense that such a connection exists. Thus, the identified "pattern of omission," arising from authoritative biomedical theory, shared conditioning and social convention, can be seen as contributing to the reluctance both of doctors and of patients to address certain topics.

The third analytical pattern traces the impact that biomedically engendered and enacted patterns of presuppositions have such that narratives of salient lifetime experiences are prevented from entering clinical encounters; this concerns both the information doctors hesitate to elicit from their patients and the information patients hesitate to relate to their doctors. This 
phenomenon has been explored extensively by, among other scholars, Eric Cassell, who has emphasized the importance and impact of attending to and being responsive to reports from the patient's life-world [26].

In face-to-face interviews conducted by a previously unknown physician-researcher on the basis of only a condensed version of information offered by their GPs, the patients in this study did not hesitate to reveal salient details of a private, intimate and at times highly emotional nature. The patients shared, for example: deep, unresolved grief resulting from the loss of an illegitimate child while involved in other very strained relationships; the fear of spousal infidelity, of being abandoned when old and sick; the anxiety linked to the risk of dying from a disease which runs in the family; the shame connected to being an illegitimate child who had been given up for adoption; the social stigma of having an alcoholic father; the secret burden of having been economically exploited by both mother and sister. (To preserve anonymity, specific references to the patients listed in Table 1 have been omitted here.)

Explanations of why such socially silenced and even taboo topics could emerge during a one-hour interview with a stranger while not having been shared with a GP during a clinical relationship that had lasted for years are bound to be complex. The most obvious and likely reason is that, as discussed above, the GPs had never explicitly invited the patients to share significant and potentially sensitive aspects of their biographies. One might argue that another explanation lies in the nature of the research setting, that it is defined as a confidential encounter, without future implications for the relationship between the informant and the researcher and without the risk that information revealed would become part of medical records to which third parties might gain access. We have not, however, encountered research evidence pointing in this direction. What does seem to be documented by studies regarding topics identified as "sensitive" is that face-to-face, open-ended research interview settings provide a better frame and result in more disclosure and more detailed reports, than do standardized questionnaires. Also, considerably more disclosure occurs in clinical settings when patients are routinely asked to disclose as compared to when they are not asked [32]. Thus, the obstacles to disclosure of lifetime adversity seem to reside less on the side of the patients. Researchers and clinicians [33-36] have been shown to demonstrate reluctance both to addressing such topics and to encouraging patients to elaborate on how unresolved and painful experiences have affected their life and health. Researchers and clinicians in particular, often seem to explain such reluctance by referring to time constraints and to the patients' vulnerability, thus framing the avoidance of certain topics as professionally and ethically justifiable [33]. However, the emerging scientific evidence appears to support the conclusion that it is a question not of whether to ask but of how to ask [37]. As recently shown by Feder and coworkers [38] clinicians who have been properly and systematically trained can adequately and supportively approach even such sensitive topics as domestic violence without doing harm.
The fourth pattern in our analysis, the pattern of personal relationship, concerns the GPs' own reactions when, during the course of the interview, they become aware of an inability to provide what they themselves would deem to be "a satisfying answer" to the researcher's questions. As previously described, their reactions included: a straightforward, unelaborated and flat statement, "No knowledge", a neutral excuse, an expression of frustration as seen above in the stated wish to have been asked about some other patient instead or an explicit expression of shock and embarrassment. The interviewer interpreted the paraverbal phenomena registered in the audio recordings of the telephone interviews as expressing astonishment, surprise, a sense of being bothered, perplexed, hesitant or embarrassed, often accompanied by short and timid laughter. Most GPs used tentative formulations, such as assumptions, suppositions and generalizations, when encountering their lack of facts or uncertainty about them. They frequently urged the interviewer to offer them comfort through confirming that such a lack of knowledge was not uncommon.

Contrary to expectations, the degree of the GP's familiarity with the patient's life-world or biography was not proportional to the duration of the patient-doctor relationships, which ranged, with one exception, from 10 to 25 years (Table1). Sympathy seemed to increase with greater familiarity with patient facts while emotional distance or even outright strain seemed to accompany a relationship with many factual "holes." Thus, the GP's explicit engagement in the patient's general state of being emerged as pivotal. For example, one GP's detailed and comprehensive presentation of the patient in the interview, even including the highly sensitive information that the patient had recently been both sexually and economically exploited and cheated, was mirrored in the patient's trustful and assertive interview comments. On the other hand, a GP's characterizing of a patient as "a very difficult person to help...very demanding...never satisfied," is reflected in the patient's comment during the interview that, "We've never had a dialogue. You and I, in the time we've been sitting here, have talked more together than my GP and I have during almost 10 years."

\section{A pattern that connects}

At this point in our theoretical reflections on our empirical findings we enter an ongoing debate of models of doctorpatient interactions, one which transcends traditional - and inadequate - dichotomies and demarcations. The discussion touches upon topics such as: patient-centered versus person-focused care [22]; how to understand "what it might mean to be a good healthcare practitioner" [39]; how to delineate "the physicians' role in patients' nursing home care" [20]; what to think about "the person in medicine" [27] and, most explicitly, the current and ongoing debate concerning "person-centered medicine as an emerging model for modern clinical practice” [13]. We note at the core of this discussion a rising concern about the expansion and the galloping financial costs, of a technology-driven healthcare system; this system appears to become increasingly de-humanizing and de- 
personalizing as only those approaches to human disease and suffering which are presumed to be 'value-neutral' and 'objective' are considered appropriate sources for the production and implementation of biomedical knowledge.

As our analysis has highlighted, salient information about patients' life-world remains unknown to the GP while being easily accessible to an attentive researcher. This provides a link to another ongoing discourse. There is a rapidly expanding body of knowledge regarding the impact on health of encountering adverse life experiences. It traces the general medical relevance of highly distressing experiences, in particular, those which are socially silenced, which engender secrecy and evoke shame [7,4048].

It is now indisputable that a heavy burden of adverse experiences has a detrimental impact on a person's physiology, on her/his embodied life. It follows, then, that GPs who care for people over time ought to express explicit interest in knowledge of such experiences. Our empirical material provides illuminating examples of adverse experiences of which GPs were unaware. Research has shown correlations between various types of adverse life experiences and constantly activated stress responses, compromised immune activity and systemic inflammation [7], accelerated biological aging $[45,46]$, disturbed brain development and dementia [49,50], complex, chronic disease patterns [7,40,41,43,44] and as an acknowledged factor contributing to intermittent admissions to nursing homes [18]. It is highly probable that precisely those life experiences that are traditionally defined as irrelevant to an understanding of human biology and healthcare, may contribute to the sudden health deterioration of someone whose condition is already compromised, such as those we encountered in our study. Consequently, it may be of particular importance for GPs' to elicit and transmit knowledge about patients' life-world, about their patients as persons, when those patients are in transition to other caretakers.

\section{Reflections on validity}

A strength of our study is that both the analytical framework and method used enabled us to explore what salient biographical knowledge GPs actually have about their patients as persons. Face-to-face, personal interviews with patients facilitated an exploration through "meaningful dialogic talk." This yielded texts that could then be both validated and elaborated, with phenomenology-hermeneutics serving as a framework for interpreting the human life-world thus revealed. The validation involved comparing the doctors' accounts to those of the patients while the elaboration involved examining the patients' accounts of previously unknown yet potentially medically relevant biographical data. The issue of what sorts of "realities" can emerge during interviews has been discussed by scholars and researchers working in a broad range of disciplines [51]. We agree with Miller and Glassner who emphasize that it is "only in the context of non-positivistic interviews, which recognize and build on their interactive components (...) that 'intersubjective depth and deep mutual understanding' can be achieved." We were cognizant while conducting this kind of interactionist research, aimed at gaining access to and insight into both patients' and doctors' meaningful worlds, that differing social contexts were at play in the 2 groups. Still, the fact that an interview might itself be seen as a symbolic interaction "does not discount the possibility that knowledge of the social world beyond the interaction can be obtained" [51].

The GPs who participated in the focus groups during the first phase of this project claimed to be knowledgeable about their patients as persons [15]. Although a different group of doctors participated in the present study, the findings indicate that physicians' knowledge is, in fact, limited and that the patterns of those limitations are shaped both by professional and social phenomena. Our findings may also be seen to illustrate the well-documented discrepancy between doctors' ways of thinking (attitude, point of view) and doing (actual practice) [52].

One might argue that each participating GP was interviewed about one relatively incidental patient only and we do not claim the findings in this study to be representative for all GPs and all GP-patient relations. The emerging patterns of "present" and "absent" knowledge however evoked recognition among the researchers in our group, where all authors have long clinical experience from primary care in addition to their academic training. In accordance with the traditions of phenomenologicalhermeneutical research, we have made our position explicit and aimed for methodological transparency. We have integrated the findings using relevant theoretical frameworks to unfold their implicit features, well-aware that our conclusions are tentative and represent only one of a variety of possible interpretations.

\section{Conclusions and Implications}

The present study contributes to a growing and increasingly coherent body of theoretical knowledge and empirical evidence indicating a recent, strong and perhaps paradigmatic increase in interest within medical thought and practice regarding the patient as a person. We are convinced that the current crisis in medicine, with its costly and limitlessly expanding focus on technology, is essentially a crisis of knowledge, a crisis of care, compassion and trust. This is not a question of quantity, as in, "not enough knowledge." Rather, it is a 2-fold form of inadequate knowledge: inadequate knowledge production - resulting from a hesitance to grasp the shortcomings of medicine's traditional perspectives on what constitutes knowledge about the human body; and inadequate knowledge implementation - resulting from a hesitance to apply the wealth of already existing knowledge regarding the interrelatedness of biology and biography [8]. The challenge which the medical profession faces is the need for a kind of knowledge that reflects the fact that human beings are lived bodies, or, as phenomenological philosopher Maurice Merleau-Ponty has put it: a body we have (object) - yet different from all other objects - and a body we are (subject) [14]. The ambiguity inherent in this 
dual status of the human body is an inevitable feature of the human condition.

Based as it is on evidence - impersonal, fragmented and de-contextualized in its nature - the current gold standard of clinical practice is too limited to serve as the foundation of an appropriate approach. It must be expanded to include models that facilitate an explicitly personalized and contextualized clinical practice. The most central source of this different approach lies precisely in knowledge traditionally regarded as private or personal and thus neglected: the first-person accounts of the subjects themselves, those who suffer and are in need of help. This is something GPs actually need to know and learn to address. However, we are talking about sensitive issues that need to be handled with competence and care. Further research, reflection and professional maturation in the GP community is needed before systematic attempts to change current practice are advisable.

\section{Acknowledgments and declaration of conflicts of interest}

We thank Susan Schwartz Senstad for constructive advice and for editing our manuscript. The authors declare no conflicts of interest with respect to the authorship and/or publication of this article. The first author disclosed receipt of the following financial support for the research and authorship of this article: The Norwegian College of General Practice, The Norwegian Committee on Research in General Practice and 'Nidarosfondet til fremme av allmennmedisinen i Trøndelag' (Nidarosfondet for support of General Practice in Trøndelag County).

\section{References}

[1] Farmer, P. (2005). Pathologies of power: health, human rights, and the new war on the poor. $2^{\text {nd }}$ Edition. Berkeley: University of California Press.

[2] Lanius, R.A., Vermetten, E. \& Pain, C. (eds.). (2010). The impact of early life trauma on health and disease: the hidden epidemic. Cambridge: Cambridge University Press. [3] Marmot, M. (2006). Health in an unequal world. Lancet 368 (9552) 2081-2094.

[4] Read, J., Mosher, L.R. \& Bentall, R.P. (2004). Models of madness: psychological, social and biological approaches to schizophrenia. London: Routledge.

[5] Seeman, T., Epel, E., Gruenewald, T., Karlamangla, A. \& McEwen, B.S. (2010). Socio-economic differentials in peripheral biology: cumulative allostatic load. Annals of The New York Academy of Sciences 1186, 223-239.

[6] Kemeny, M.E. (2009). Psychobiological responses to social threat: evolution of a psychological model in psychoneuroimmunology. Brain, Behavior, and Immunity 23 (1) 1-9.

[7] Danese, A. \& McEwen, B.S. (2012). Adverse childhood experiences, allostasis, allostatic load, and agerelated disease. Physiology \& Behavior 106 (1) 29-39.
[8] Getz, L., Kirkengen, A.L. \& Ulvestad, E. (2011). The human biology- saturated with experience. Tidsskrift for Den norske Legeforening 131 (7) 683-687.

[9] Frank, A.W. (1995). The wounded storyteller: body, illness, and ethics. Chicago: University of Chicago Press.

[10] Kleinman, A. (1988). The illness narratives: suffering, healing and the human condition. New York: Basic Books. [11] Leder, D. (ed.). (1992). The Body in medical thought and practice. Dordrecht: Kluwer Academic Publishers.

[12] Scaer, R.C. (2001). The body bears the burden: trauma, dissociation, and disease. New York: Haworth Medical Press.

[13] Miles, A. \& Mezzich, J.E. (2011). The care of the patient and the soul of the clinic: person-centered medicine as an emergent model of modern clinical practice. International Journal of Person Centered Medicine 1 (2) 207-222.

[14] Kirkengen, A.L., Mjølstad, B.P., Getz, L., Ulvestad, E. \& Hetlevik, I. (2012). Can person-free medical knowledge inform person-centred medical practice? European Journal for Person Centered Healthcare. In press.

[15] Mjølstad, B.P., Kirkengen, A.L., Getz, L. \& Hetlevik, I. (2012). Knowing patients as persons. Senior and Junior GPs explore a professional resource. European Journal for Person Centered Healthcare. In press.

[16] Nasjonalt folkehelseinstitutt. (2010). Folkehelserapporten 2010: Helsetilstanden i Norge. Rapport 2010: 2. Oslo: Nasjonalt folkehelseinstitutt. [The Status of Public Heath in Norway 2010][Norwegian]. Available at : www.fhi.no/dokumenter/f5894f100f.pdf, (Last acessed: May 8 2013).

[17] Brevik, I. \& Schmidt, L. (2005). Slik vil eldre bo. [How older people want to live] [Norwegian]. Oslo; NIBR Rapport 2005:17.

[18] Luppa, M., Luck, T., Weyerer, S., König, H.H., Brähler, E. \& Riedel-Heller, S.G. (2011). Prediction of institutionalization in the elderly. Systematic review. Age and Aging 39 (1) 31-38.

[19] Gaugler, J.E., Duval, S., Anderson, K.A. \& Kane, R.L. (2007). Predicting nursing home admission in the US; a meta-analysis. BMC Geriatrics 7, 13.

[20] Zweig, S.G., Popejoy, L.L., Parker-Oliver, D. \& Meadows, S.E. (2011). The physician's role in patients' nursing home care: "She's a very courageous and lovely woman. I enjoy caring for her". Journal of the American Medical Association 306 (13) 1468-1478.

[21] Gordon, D.R. (1988). Tenacious assumptions in Western medicine. In: Biomedicine examined. Lock, M. \& Gordon, D.R. (eds.). Dordrecht: Kluwer Academic Publishers.

[22] Starfield, B. (2011). Is patient-centered care the same as person-focused care? The Permanente Journal 15 (2) 63-69.

[23] Kvale, S. (1983). The qualitative research interview: A phenomenological and a hermeneutical mode of understanding. Journal of Phenomenological Psychology 14 (2) 171-196.

[24] Mishler, E.G. (1986). Research interviewing: context and narrative. Cambridge, Mass.: Harvard University Press. 
[25] Mishler, E.G. (1999). Storylines: craftartists' narratives of identity. Cambridge, Mass.: Harvard University Press.

[26] Cassell, E.J. (2004). The nature of suffering and the goals of medicine. 2nd Edition. Oxford: Oxford University Press.

[27] Cassell, E.J. (2010). The person in medicine. International Journal of Integrated Care, 10 (Supplement) 50-52.

[28] Toulmin S. (1976). On the nature of the physician's understanding. Journal of Medicine and Philosophy 1 (1) 32-50.

[29] Mishler, E.G. (2005). Patient stories, narratives of resistance and the ethics of human care: a la recherché du temps perdu. Health 9 (4) 431-450.

[30] Zaner, R.M. (2003). Ethics and the clinical encounter. Lima, Ohio: Academic Renewal Press.

[31] Montgomery, K. (2006). How doctors think. Clinical judgement and the practice of medicine. Oxford: Oxford University Press.

[32] Read, J., Hammersley, P. \& Rudegeair, T. (2007). Why, when and how to ask about childhood abuse. Advances in Psychiatric Treatment 13, 101-110.

[33] Becker-Blease, K.A. \& Freyd, J.J. (2006). Research participants telling the truth about their lives. The ethics of asking and not asking about abuse. American Psychologist 61 (3) 218-226.

[34] Read, J. (2007). To ask, or not to ask, about abuse New Zealand Research. American Psychologist 62 (4) 325326, discussion 330-332.

[35] Sugg, N.K. \& Inui, T. (1992). Primary care physician's response to domestic violence: opening Pandora's box. Journal of the American Medical Association 267 (23) 3157-3160.

[36] Sugg, N.K., Thompson, R.S., Thompson, D.C., Maiuro, R. \& Rivara, F.P. (1999). Domestic violence and primary care. Attitudes, practices, and beliefs. Archives of Family Medicine 8 (4) 301-306.

[37] Edwards, V.J., Dube, S.R., Felitti, V.J. \& Anda, R.F. (2007). It's ok to ask about past abuse. American Psychologist 62 (4) 327-329.

[38] Feder, G., Davies, R.A., Baird, K., Dunne, D., Eldridge, S., Griffiths, C., Gregory, A., Howell, A., Johnson, M., Ramsay, J., Rutterford, C. \& Sharp, D. (2011). Identification and referral to improve safety (IRIS) of women experiencing domestic violence with a primary care training and support programme: a cluster randomised controlled trial. Lancet 378 (9805) 1788-1795.

[39] Duncan, P. \& Stephenson, A. (2011). Dealing with systems and understanding contexts: what it might mean to be a 'good health care practitioner'. Journal of Evaluation Clinical Practice 17 (5) 964-969.

[40] Felitti, V.J. \& Anda, R.F. (2010). The relationship of adverse childhood experiences to adult medical disease, psychiatric conditions and sexual behavior: implications for healthcare. In: The impact of early life trauma on health and disease. The hidden epidemic. Lanius, R.A., Vermetten, E. \& Pain, C. (eds.). Cambridge: Cambridge University Press.

[41] Pesonen, A.K., Raikkonen, K., Feldt, K., Heinonen, K., Osmond, C., Phillips, D.I., Barker, D.J., Eriksson, J.G.
\& Kajantie, E. (2010). Childhood separation experience predicts HPA axis hormonal responses in late adulthood: a natural experiment of World War II. Psychoneuroendocrinology 35 (5) 758-767.

[42] Kajantie, E. \& Raikkonen, K. (2010). Early life predictors of the physiological stress response later in life. Neuroscience and Biobehavioral Reviews 35 (1) 23-32.

[43] Fuller-Thomson, E., Brennestuhl, S. \& Frank, J. (2010). The association between childhood physical abuse and heart disease in adulthood: findings from a representative community sample. Child Abuse \& Neglect 34 (9) 689-698.

[44] Glaser, R. \& Kiecolt-Glaser, J.K. (2005). Stressinduced immune dysfunction: implication for health. Nature Reviews Immunology 5 (3) 243-251.

[45] Kiecolt-Glaser, J.K. \& Glaser, R. (2010). Psychological stress, telomeres, and telomerase. Brain, Behavior and Immunity 24 (4) 529-530.

[46] Kananen, L., Surakka, I., Pirkola, S., Suvisaari, J., Lönnquist, J., Peltonen, L., Ripatti, S. \& Hovatta, I. (2010). Childhood adversities are associated with shorter telomere length at adult age both in individuals with an anxiety disorder and controls. PloS ONE 5 (5) e10826.

[47] Lovallo, W.R., Farag, N.H., Sorocco, K.H., Cohoon, A.J. \& Vincent, A.S. (2012). Lifetime adversity leads to blunted stress axis reactivity: studies from the Oklahoma Family Health Patterns Project. Biological Psychiatry 71 (4) 344-349.

[48] Slavich, G.M., O'Donovan, A., Epel, E.S. \& Kemeny, M.E. (2010). Black sheep get the blues: a psychobiological model of social rejection and depression. Neuroscience and Biobehavioral Reviews 35 (1) 39-45.

[49] Teicher, M.H., Samson, J.A., Sheu, Y.S., Polcari, A. \& McGreenery, C.E. (2010). Hurtful words: association of exposure to peer verbal abuse with elevated psychiatric symptom scores and corpus callosum abnormalities. American Journal of Psychiatry 167 (12) 1464-1471.

[50] Lupien, S.J., McEwen, B.S., Gunnar, M.R. \& Heim, C. (2009). Effects of stress throughout the lifespan on the brain, behaviour and cognition. Nature Reviews Neuroscience 10 (6) 434-445.

[51] Miller, J. \& Glassner, B. (2006). The “inside” and the "outside". Finding realities in interviews. In: Qualitative research. Theory, Method and Practice. 2nd edn. Silverman, D., (ed.). London: Sage Publications.

[52] Hetlevik, I., Getz, L. \& Kirkengen, A.L. (2008). Allmennleger som ikke følger retningslinjer - kan de ha sine grunner? [General practitioners who do not adhere to guidelines - do they have valid reasons?] [Norwegian] Tidsskrift for Den norske Legeforening 128 (19) 22182220. 